\title{
LITERATURA PÓS-COLONIAL E HISTÓRIA POLÍTICA DE ANGOLA E NIGÉRIA: A FICÇÃO CONTEMPORÂNEA
}

\author{
POST-COLONIAL LITERATURE AND POLITICAL HISTORY OF ANGOLA AND \\ NIGERIA: THE CONTEMPORARY FICTION
}

Adilson Vagner Oliveira ${ }^{1}$

Recebido em 30/03/2021

Aceito em 03/01/2022

Resumo: Este trabalho estabelece um diálogo entre as narrativas literárias pós-coloniais africanas, tendo como enfoque principal a política e sua forma de representação literária em obras ficcionais. Em termos metodológicos, foram utilizados os procedimentos de literatura comparada, proposto por Tânia Carvalhal (2006), em que se analisaram produções literárias de Nigéria e Angola, evidenciando como a história política dos dois países foram representados em cada romance. As obras analisadas foram Hibisco Roxo (2011) e Meio Sol Amarelo (2008) de Chimamanda Ngozi Adichie e O Planalto e a Estepe (2009) de Pepetela.

Palavras-chave: Literatura Africana, Engajamento, Literatura Comparada.

Abstract: This paper establishes a dialogue between the post-colonial African literary narratives, having as main focus the politics and its form of literary representation in fictional works. In methodological terms, the comparative literature procedures proposed by Tânia Carvalhal (2006) were used, in which literary productions from Nigeria and Angola were analyzed, showing how the political history of the two countries was represented in each novel. The analyzed works were Purple Hibiscus (2011) and Half of a Yellow Sun (2008) by Chimamanda Ngozi Adichie and O Planalto e a Estepe (2009) by Pepetela.

Keywords: African Literature, Engagement, Comparative Literature.

\section{Introdução}

A representação ficcional dos fenômenos políticos da África tem sido uma agenda muito significativa nos estudos de literatura comparada recentemente. Trata-se de uma escrita literária engajada, construída sobre um alicerce dialógico entre política e sociedade. Dessa maneira, as narrativas pós-coloniais do continente africano são

Doutor em Ciências Políticas pela Universidade Federal de Pernambuco (UFPE). Docente do Instituto Federal de Mato Grosso (IFMT). Contato: adilsontga@msn.com 
desenvolvidas por meio de análises críticas da realidade, em que são evidenciados os conflitos históricos que atingiram as nações e seus povos recentemente.

É interessante acrescentar que o continente africano passou por um complexo processo de colonização, marcado por conflitos étnicos, econômicos e sociais, consequentemente o cenário político tornou-se instável, ao longo das décadas pósindependência, o que resultou em diversas revoltas populares e crises políticas. Após o processo de descolonização em países africanos, os colonizados passaram a produzir suas próprias obras literárias. Desse modo, a escrita africana buscou disseminar uma série de produções narrativas, marcadas pelo engajamento e crítica aos processos histórico e político, tão prejudiciais aos povos africanos.

Neste trabalho, foram evidenciadas as manifestações de características de engajamento presentes nas literaturas pós-coloniais de Angola e Nigéria, tendo como principal objetivo realizar a análise literária de obras ficcionais e estabelecer um parâmetro comparativo entre elas, expondo de que maneira os fenômenos políticos são materializados em cada romance. Para isso, foi utilizado o método comparado, descrito por Carvalhal (2006), utilizando-se as obras literárias Hibisco Roxo (2011) e Meio Sol Amarelo (2008) de Chimamanda Adichie e O Planalto e a Estepe (2009) de Pepetela.

\section{A presença do engajamento político nas literaturas pós-coloniais}

A literatura pós-colonial africana é marcada pela discussão de vários aspectos que condizem com realidade apresentada em escala global, tais como os fatores sociais, políticos e históricos ligados ao colonialismo, governos e regimes políticos ditatoriais. Dentre esses, pode-se ressaltar a forte presença do engajamento político, evidenciado pelo discurso histórico sobre a política de Angola e Nigéria, ao longo do século XX.

Para Rancière (2004), a política na literatura é definida pela forma da escrita, havendo uma ligação entre a maneira como é posta a política e o próprio discurso ficcional, tornando-a uma literatura. "O sintagma 'política da literatura' significa que a literatura 'faz' a política como literatura - que existe uma ligação específica entre a política, como forma definitiva de fazer a literatura uma prática definida de escrita" (RANCIÈRE, 2004, p. 10. Tradução nossa.). 
A literatura engajada é caracterizada, principalmente, por um autor que faça política em suas próprias obras, ou seja, que usa seus livros como instrumento político que possa alcançar todos os seus leitores, abrangendo diversos públicos (DENIS, 2002). "Engajado na mesma aventura que os seus leitores e situado, como eles, numa coletividade sem divisões, o escritor, ao falar deles, falaria de si mesmo e, ao falar de si mesmo, falaria deles" (SARTRE, 2004, p. 118).

O autor de literatura engajada aborda em sua escrita algo que ele acredita, desvendando os enigmas políticos conforme sua percepção, retratando tanto aspectos positivos quanto negativos da política, por meio de elementos que buscam a criticidade. Portanto, a literatura engajada é o reflexo do posicionamento do escritor, visto que, é “impossível separar o homem político do escritor, pois este deve escrever suas experiências calcadas na realidade, mesmo que o conteúdo de sua ficção possa estar distante no tempo ou no espaço" (ESTEVAM, 2011, p.13).

Todo prosador, na medida em que deseja se comunicar e que suas palavras se mostram como espelho crítico da sociedade e do mundo em que vive, é engajado, e por isso esse engajamento só pode ser entendido na concretude histórica na qual o escritor e seus leitores se situam (MOREIRA, 2012, p.15).

Dessa forma, pode-se dizer que as escritas literárias, como um todo, possuem características em comum, tais como os aspectos políticos e a maneira como são descritos em cada romance estabelece um parâmetro de semelhança entre ambos. Em outras palavras, os níveis de engajamento da literatura podem ser diferentes em objetivos, de acordo com a movimentação dos escritores pelo cenário de discussão pública, sobre o contexto político e cultural de seus países, porém, todas as obras possuem um diálogo estrutural e temática com a sociedade em que se inserem.

\section{As manifestações políticas na obra de Pepetela}

O romance de Pepetela, "O planalto e a estepe" (2009), caracteriza-se por suas discussões políticas e sociais, como plano de fundo para uma narrativa amorosa. Trata-se de uma obra ficcional dialógica com a expansão global do socialismo, na segunda metade do século XX, com destaque para o estabelecimento da União Soviética, o socialismo 
implantado na Rússia, Mongólia e Angola, assim como o capitalismo predominante em Portugal.

Na obra de Pepetela, o protagonista Júlio é um jovem angolano, de classe média alta que presencia em seu país, o início do processo de descolonização do domínio português, os quais eram, por muitas vezes, opressores dos africanos, por considerá-los uma raça inferior e incapaz de evoluir, tornando-os pessoas que não possuíam direito em seu próprio país (PEPETELA, 2009, p. 23).

Sempre foi argumento principal dos europeus para colonizar outras nações, o direito à comparação entre culturas numa hierarquia, o que lhes dava tranquilidade de espírito para apregoarem estar a civilizar os indígenas, incultos, bárbaros, selvagens. Como comparar passados e experiências? (PEPETELA, 2009, p. 157).

Em busca de uma vida melhor, por não possuir universidades em Angola, o rapaz decide cursar uma faculdade fora e Portugal é seu destino, espaço marcado pelo sistema capitalista. Entretanto, sofre opressão, simplesmente, pelo fato de vir do país que estava lutando pela independência de Portugal, e logo percebe que a luta não era somente por conta da revolta da Angola, mas devido às diferenças entre padrões políticos do capitalismo e socialismo.

Suportava as aulas sem rendimento e sonhava com lutas. De libertação, pois claro. Como a dos argelinos, que tinham mandado os franceses pregar para outras paragens, na terra deles não queriam mais donos estrangeiros. (PEPETELA, 2009, p.28)

Dessa maneira, Pepetela ressalta as diferenças entre o socialismo em Angola e as práticas capitalistas de Portugal, tais como a presença do autoritarismo, e atos de opressão às ideias diferentes, atacando e combatendo diretamente protestantes e rebeldes, o que gerava no povo uma espécie de medo, restringindo a liberdade de expressão. Logo, Júlio se vê obrigado a mudar-se da região para finalizar sua faculdade, escolhendo a Rússia Soviética, como próxima rota, isso se dá pela semelhança de regime com seu país de origem. Além de que a URSS estava financiando os angolanos na luta contra os domínios de Portugal, por fortes interesses políticos estrangeiros.

$\mathrm{E}$ aos poucos, percebe que o socialismo também possuía incoerências, enquanto sistema político e econômico. Todavia, assim como no capitalismo, as autoridades também não se permitiam ser contrariadas, por isso, Júlio evitava expor suas opiniões. 
Quando terminámos o curso de Economia, Jean-Michel regressou a Brazzaville, ansioso por participar na revolução em curso no seu país. O socialismo tinha sido instaurado como doutrina oficial do regime. As cartas que me escrevia contavam dos seus sonhos e suas esperanças. Arranjou emprego no gabinete de um ministro, foi subindo muito rapidamente na Juventude do Partido no poder. (...) As suas cartas denotavam desespero por estar a colaborar com uma farsa, qual socialismo qual nada, só pensam em mulheres e carros, já que enriquecer é difícil em terra tão pobre. (...) Pobre África. (PEPETELA, 2009, p. 39).

Na universidade russa, conhece Sarangerel, seu grande amor. Porém, após meses de namoro, Júlio recebe duas notícias oriundas da namorada: que ela está grávida e que o pai da garota era um líder socialista da Mongólia. Ambos decidem começar a planejar o casamento, o que não se concretiza por causa das relações políticas da família de Sarangerel, visto que era preciso que se relacionassem com alguém de negócios e não com um homem comum e de origem africana, pois "na fábula da vida, algumas misturas são toleradas" (Pepetela, 2009, p. 89).

Para não prejudicar a posição e acordos políticos de sua família, Sarangerel é levada de forma forçada a seu país, impedindo qualquer tipo de comunicação com Júlio, o que tornou o reencontro possível somente décadas depois.

Afastaram-nos um do outro só por sermos de países diferentes, por um ter olhos castanhos e outro azuis. E ao mesmo tempo gritavam vivas ao internacionalismo e à amizade eterna entre os povos. Tudo mentira! (PEPETELA, 2009, p. 155).

Aos poucos, o personagem percebe que o socialismo teórico possuía inúmeras divergências da prática, o que propiciou sua queda, anos depois, devido, exatamente, às contradições internas do sistema e às revoltas que discutiam a sua forma autoritária de governo. Assim, a trajetória de Júlio por países socialistas, na segunda metade do século XX, revela o projeto estético da ficção angolana, ao revisitar a história política do país e ficcionalizar fenômenos históricos do país.

A obra de Pepetela atribui ao relacionamento amoroso entre Júlio e Sarangerel uma centralidade narrativa, porém, constrói o enredo de desencontros afetivos em cima de um território geopolítico de carácter profundamente globalizado. Personagens ficcionais, com importância literária para a composição contemporânea de Angola, pois, não somente atualiza o romance africano, mas investiga no passado histórico do país, efeitos políticos na atualidade. 


\section{O engajamento político no romance "Hibisco Roxo" de Chimamanda}

Chimamanda Ngozi Adichie é uma escritora nigeriana que em suas produções literárias procura retratar, através de narrativas robustas, o processo político e social de enorme complexidade enfrentado pela Nigéria no decorrer do século XX. Em sua obra Hibisco Roxo (2011), ela descreve o golpe de estado enfrentado pelo país nos anos de 1970, através da perspectiva narrativa de uma jovem introvertida que está exposta aos diversos fatores políticos e econômicos de impacto sobre o país. A partir de uma visão proveniente da elite econômica da Nigéria, ligada às maiores empresas nacionais e meios de comunicação em embate constante, com a força política dos governos autoritários locais, em diferentes décadas, da história da Nigéria.

Kambili é uma garota de quinze anos que vive na Nigéria, um dos países mais dinâmicos economicamente da África, até os dias de hoje. A jovem faz parte da alta sociedade local, portanto, possui boas condições financeiras, seu posicionamento perante a sociedade advém de seu pai, que é um homem poderoso e influente na política local. Porém apesar dos privilégios que detém, Kambili, seu irmão Jaja e sua mãe Beatrice precisam lidar com a inflexibilidade e o comportamento violento do personagem Eugene, que através de fortes discursos religiosos impõe regras de caráter extremistas e expõe sua família a comportamentos agressivos e hostis.

A política nigeriana encontrava-se em um período crítico, em decorrência dos golpes de Estado, no país recém independente, portanto, um governo totalitário e opressivo adentra o comando da sociedade, provocando uma série de revoltas populares, assassinatos, prisões e conflitos políticos.

Na primeira semana após o golpe, Kevin passou a arrancar galhos com folhas verdes das árvores e enfiá-los na placa do carro, para que as pessoas que protestavam na Government Square nos deixassem passar. Os galhos significavam solidariedade (ADICHIE, 2011, p. 33).

Kambili entra em contato com as informações referentes à crise do país, por meio de diálogos que presencia de seu pai Eugene, que é dono do Standard, um jornal que visa à crítica social e expõe a realidade local, a partir de denúncias e enfrentamentos públicos com o governo nacional. Ela descreve o jornal de seu pai, como um dos únicos que se 
posiciona contrário ao golpe, o que o leva a sofrer diversas tentativas de suborno e opressão.

No dia seguinte ao golpe, antes de sairmos para receber a benção noturna em St. Agnes, ficamos sentados na sala de estar lendo os jornais; nosso entregador trazia quatro edições de cada um dos principais jornais todas as manhãs, por ordem de Papa. Lemos o Standard primeiro. Só ele publicara um editorial crítico, pedindo que o novo governo militar rapidamente implementasse um plano de retorno à democracia. (ADICHIE, 2011, p. 31).

Devido aos conflitos políticos e às constantes ameaças que Eugene recebia do governo militar, ele envia seus dois filhos para casa de sua irmã Ifeoma, mãe solteira, professora universitária que lutava em prol da liberdade e da verdadeira democracia para o país. Por ser muito influente na universidade no qual trabalhava, Ifeoma foi acusada de fomentar manifestações e revoltas feitas pelos seus alunos, esses incendiaram a residência do administrador e os carros que estavam no estabelecimento universitário. Certo dia a mulher se depara com a chegada de militares armados em sua casa, eles buscavam algo que pudesse incriminá-la, de calúnia e difamação contra o Governo.

Estamos aqui para fazer uma busca em sua casa. Estamos procurando documentos cujo objetivo é sabotar a paz da universidade. Fomos informados de que você está colaborando com os grupos de estudantes radicais que organizaram os protestos... (ADICHIE, 2011, p. 243).

Kambili absorve diversos diálogos vindos de sua tia, nos quais ela demonstra sua revolta com a situação da população e com as más condições econômicas e políticas enfrentadas pelo povo, ela cita diversas vezes que não recebe a seu salário há meses, devido à suposta falta de dinheiro do governo. Ifeoma também se sente oprimida e censurada quando ministra suas aulas, além de que não ter o direito de expressar sua liberdade de opinião, dentro do ambiente universitário.

- Disseram que há uma lista circulando por aí, Ifeoma, de professores que são desleais à universidade. Disseram que essas pessoas podem ser demitida. Disseram que seu nome está na lista.

- Não sou paga para ser leal. Quando falo a verdade, vira deslealdade. - Mas, gwakenem, por acaso a verdade vai alimentar seus filhos? (...)

— E quando é que nós vamos protestar, ê? Quando os soldados virarem professores e os alunos tiverem de ir às aulas com armas apontadas para a cabeça? Quando nós vamos protestar? (ADICHIE, 2011, p. 234-235).

Cansada dos conflitos políticos, da falta de oportunidades e liberdade de expressão, Ifeoma e seus filhos se mudam para os Estados Unidos, em busca de melhor 
qualidade de vida. Contudo, oferecem à protagonista da obra momentos singulares de aprendizagem histórica e política sobre a Nigéria, e reforçam o papel das elites econômicas do país em lutar pela liberdade política e transformar a sociedade africana. Kambili e sua família continuam na Nigéria, mas com a morte repentina de seu pai, assassinado por Beatrice, e a prisão de irmão, sua vida muda drasticamente. Apesar da crise enfrentada por seu povo, agora a garota sente que tem voz e que pode comandar sua vida e escrever a própria história, em consonância à história da Nigéria contemporânea.

\section{Os fenômenos políticos na literatura de Chimamanda Adichie}

Na obra Meio sol amarelo (2008), de Chimamanda Adichie, é retratada a história política nigeriana na década de 1960, marcada por inúmeros conflitos políticos advindos da separação de etnias entre diferentes povos nigerianos, sendo eles os igbos, iorubás, e hauçás, esses fatores forçaram a criação do Estado de Biafra, no oeste da Nigéria. Nessa narrativa, é evidenciada a luta pelo poder e a representação da Guerra Civil do país, recém independente.

Nessa robusta narrativa de Chimamanda, a autora resgata o conflito étnico e político da Nigéria que exigiu a criação de um novo território independente, com a separação da população igbo do restante do país. Trata-se de uma reflexão importante que pode ser aplicado a várias nações africanas que se defrontaram com os mesmos dilemas de unificação política, após a independência. Em regiões plurais etnicamente, a construção da nação nigeriana baseou-se também no conflito étnico, na organização do poder central e no desenvolvimento político do país.

O romance narra a vida de Ugwu, um garoto camponês que vem trabalhar, como empregado doméstico, na casa de Odenigbo, um professor da Universidade de Nsukka. Seu chefe é casado como uma igualmente professora universitária que havia estudado em Londres, a mulher vem de uma família de classe alta e é filha de empresário de Lagos, capital do país. O jovem, através da convivência com o casal, vai modificando sua percepção sobre o mundo e a política conturbada de seu país.

O jovem vivencia o Golpe de Estado que ocorre na Nigéria em 1966, o que leva ao início de uma guerra civil no país. A obra se concentra na vida destes três personagens e suas lutas para criar um Estado novo para a etnia igbo, com o objetivo de separar uma 
parte do território da Nigéria e criar um governo independente, a terra do meio sol amarelo, Biafra.

A escrita de Chimamanda faz referência aos diversos momentos históricos da Nigéria, os conflitos armados, a complexidade da política local e as diversas cidades destruídas pela guerra se materializam nos caminhos políticos seguidos pelo país, durante anos.

\begin{abstract}
A constituição foi suspensa, e os governos regionais e as assembleias eleitas foram dissolvidos. Meus queridos compatriotas, o objetivo do Conselho Revolucionário é estabelecer uma nação livre de corrupção e de lutas internas. Nossos inimigos são os aproveitadores políticos, os vigaristas, aqueles que ocupam tanto altos postos quanto cargos de segundo escalão e que exigem suborno de dez por centro, são os que procuram manter o país permanentemente dividido para continuar lucrando, são os tribalistas, os nepotistas, aqueles que fazem nosso país parecer bom para coisa nenhuma nos círculos internacionais, aqueles que corromperam a nossa sociedade (ADICHIE, 2008, p. 148).
\end{abstract}

A passagem acima é uma fala dita através de um anúncio de rádio, após o Golpe de Estado, que resulta no medo da população por causa das diversas transformações que estão ocorrendo no país, sendo elas, o conflito étnico armado, o genocídio, a fundação do Estado de Biafra e a luta pelo poder central nigeriano. Como consequência, a guerra civil começa a avançar e gerar a fuga da população de diversas regiões, devido à violência dos ataques, às mortes e à fome enfrentada pela maioria da sociedade. Através disso a vida das personagens muda, radicalmente, levando a um enredo constituído de uma rica história e conflitos sociais nigerianos.

A progressão da violência política e militar sobre o país acompanha a trajetória amorosa de Odenigbo e Olanna, conturbados internamente pelos próprios conflitos relacionais do casal, tiveram que lidar com a expansão da opressão política sobre a população, inclusive aqueles pertencentes à elite cultural e econômica do país. Os dois professores universitários viram suas vidas igualmente destruídas por questões políticas e sentimentais, num processo de interação destrutiva para a paz do casal e do país.

\title{
6. Considerações finais
}

As literaturas da África pós-colonial apresentam grande representatividade, dentro de uma perspectiva mais sensível da escrita engajada. Os romances ficcionais são 
utilizados como ferramentas para desenvolver os pensamentos críticos sobre a história do continente e apresentar os diversos conflitos políticos, enfrentados ao decorrer das primeiras décadas de independência de alguns dos países africanos. Autores como Pepetela e Chimamanda Adichie se utilizaram do material histórico e do engajamento político para construção de suas obras, sendo desenvolvido enredos que demonstram a busca pela construção de identidades nacionais e processos de amadurecimento político.

As obras analisadas caracterizam-se, principalmente, pelo diálogo entre a realidade e a ficção, sendo apresentadas, subjetivamente, as manifestações políticas ocorridas no decorrer do século XX, na Nigéria e em Angola. A partir da construção literária tem sido possível identificar o desejo dos autores em dizer algo à população e aos núcleos de poder concentrado, primeiramente, a necessidade de conhecer a própria história, evidenciando a importância do desenvolvimento da escrita política e engajada, como alternativa de autoconhecimento. Em seguida, pela urgência da criação de oportunidades de fortalecimento político, para se pensar a reconstrução econômica do país, uma vez que destruídos os empreendimentos coloniais, as elites africanas precisaram lidar com a responsabilidade de assumir o controle pelo próprio crescimento do país.

\section{Referências}

ADICHIE. C. N. Hibisco Roxo. $1^{\text {a }}$ ed. São Paulo: Companhia de Letras, 2011.

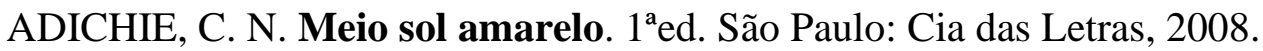

CARVALHAL, T. F. Literatura Comparada. 4.ed. São Paulo: Ática, 2006.

DENIS, B. Literatura e engajamento: de Pascal a Sartre. São Paulo: EDUSC, 2002.

ESTEVAM, M. Literatura e Política, de ontem e de hoje. Disponível em: <https://www.al.sp.gov.br/repositorio/bibliotecaDigital/21075_arquivo.pd> Acesso em: 22 de Setembro de 2018.

MOREIRA, M. F. Em torno da literatura engajada: Sartre e o debate estético.(2012) Disponível <http://bdm.unb.br/bitstream/10483/4033/1/2012_MayaraFrancaMoreira.pdf> Acesso em 22 de setembro 2018.

OLIVEIRA, A. V. Literatura e política: as contradições do socialismo em "O planalto e a estepe”. Revista Ecos vol. 16, Ano XI; nº 01, 2014.

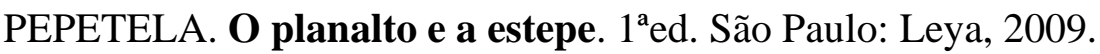


RANCIÈRE, J. The Politics of Literature. SubStance, Issue 103 Volume 33, nº 1, 2004 pp. 10-24 | 10.1353/sub.2004.0012.

SARTRE, Jean-Paul. Que é a literatura? São Paulo: Ática, 2004. 